\title{
2. NIRG and Nuclearism in the Era of Climate Change
}

\section{Laurel MacDowell}

Laurel MacDowell is professor emerita of the Department of History, University of Toronto and founder of the Nuclear International Research Group (NIRG). She has published three books, many articles and has edited or been a contributor to other books. Most recently she was the editor of the recent Nuclear Portraits, University of Toronto Press, 2017, and contributed a chapter on nuclear power to Ruth Sandwell ed. Powering Up: The History of Power, Fuel, and Energy from 1600, McGill-Queen's University Press, 2016.

laurel.macdowell@utoronto.ca

The Nuclear International Research Group (NIRG) began as I was thinking about the relationship between nuclear energy and the environment. I was also reading a great deal about climate change. One day I saw a huge billboard that boasted about what a green source of energy nuclear power was. Because I had just finished an article on uranium mining in northern Ontario, which resulted in a health disaster and became the situation that led directly to the passage of an Occupational Health and Safety Act in Ontario Canada, I found the billboard opportunistic.

There needed to be more information about the nuclear industry in the public sphere. I knew Anna Stanley who worked in the nuclear field as a geographer. She had mentioned how isolated nuclear scholars sometimes felt. So, the two things came together - my annoyance about the billboard and Anna's comment about the lack of community in the nuclear research area. The two of us decided to try to organize a group of nuclear scholars. With the Internet and Listservs how difficult could it be? 
In August 2008, an invitation went out to faculty and graduate students across Canada inviting them to join the Nuclear Research Group. The purpose of the group was to develop a small community which could discuss its interdisciplinary work and get feedback. A secondary purpose was to explore the possibility of getting funding for a workshop that critically considered aspects of production in Canada and the United States (e.g. nuclear and energy policy, health and environmental effects of radioactivity, social/environmental justice issues, historical and contemporary geographies of nuclear development, labour and occupational issues, etc.). Several people responded to our outreach.

Then Anna left for a job in Ireland. In May 2009, there was a founding meeting of the Group at the University of Ottawa. About ten people showed up. They suggested that "international" be added to the name so we became NIRG, and after our deliberations, we had a plan. We would introduce the group with a symposium, then have a larger research seminar, and then there should be a book focusing on the impact of the nuclear industry on local communities. And I should implement all of this as Coordinator.

In November 2009, the first small symposium took place in the Department of History at the University of Toronto. We had three speakers and participants, including graduate students, First Nations activists, environmentalists, Ontario Power Generation employees and some curious people from the nuclear industry. Among the speakers was Allison Macfarlane, former chairman of the Nuclear Regulatory Commission, whom President Barack Obama had named to the Blue Ribbon Commission on America's Nuclear Future. She is married to Hugh Gusterson, who had joined NIRG early, and he had suggested her. ${ }^{1}$ As a result of the symposium, several 
more people became members of NIRG, so we had twenty-eight active researchers in different fields in North America working on various aspects of the nuclear industry, including history, geography, public policy, international relations, health, environment and waste management.

The next project was funded by the SSHRC Aid to Conferences and Workshops grant. The two-day symposium, "The Nuclear Industry in the 21st Century Environment," was held at the University of Toronto in 2015. Lisa Rumiel, then at McMaster University, helped organize this event, and a larger group attended, including Robert Anderson, the editor of this book. Excellent papers presented on a range of subjects were followed by lively discussions. The twoday workshop aimed to continue the conversation about how nuclear technology has transformed the politics, cultures, economies, ways of living, public health and landscapes in nations around the world. The papers featured research by a group of scholars and graduate students from a variety of university departments and institutes around the world. The topics examined aspects of nuclear history in Canada, the United States, the Soviet Union, the European Union, the Marshall Islands, Italy, India and the continent of Africa throughout the twentieth century. The purpose of the workshop was to provide presenters with an opportunity to present their papers and discuss them with each other and with a larger audience of participants studying nuclear history. NIRG was developing a community; we gained more members, including quite a few from Europe, so we were indeed becoming more international.

With a growing email list, I tried to send out fairly regular communiques. When the Fukushima disaster struck, a great many messages were exchanged among NIRG members. This 
facilitated an ongoing connection among members so that today, members are regularly communicating about conferences, papers and ideas.

The founding meeting led to a book, Nuclear Portraits: Communities, the Environment, and Public Policy, which was published in 2017 by University of Toronto Press. Some of the chapters came out of the symposium. The one on Chernobyl, for example, was the result of Suzanne Bauer and Karena Kalmbach, who had given separate papers at the symposium, collaborating with Tatiana Kaspersi to write a broader paper on the subject for the book. Other essays were from new people, including Paul Jobin, who wrote about workers at Fukushima, and David and Marissa Bell, who wrote about ongoing conflicts in Port Hope, Canada.

As I was approaching retirement, I wanted to see NIRG continue to expand. I asked Karena Kalmbach to take over as Coordinator. She was an active scholar, young and dynamic, and fortunately, as the time was right for her, she agreed. I was delighted that NIRG had expanded beyond North America to include Europe. Karena has further developed the email list, and NIRG has been renamed and is now part of another website, so it is going in new directions. It is now "Nuclear_Hss" and staged on the website of the CNRS of France. I would like to see the organization become even more international. Today, we face the shifting situation in the Korean Peninsula, and the future of the Iran deal concerns the nuclear industry, the world and nuclear scholars. With the Iranian and North Korean nuclear programs in the news, it would be useful to attract scholars who are knowledgeable about those countries and other nuclear nations, such as India, Pakistan, Russia and Israel. Some of them are represented here. 
What NIRG has become today and what new directions it takes in the future will depend on those members, like Robert Anderson, who decide to sponsor events which facilitate discussion and result in new contacts and new scholarship. From the beginning, there was always a relationship in my mind between the nuclear file and the environment, with a concern about the proliferation of nuclear production with possible military dimensions. But climate change must also be a subject of concern to nuclear researchers. I presume that fewer nuclear nations and nuclear plants are desirable to prevent nuclear war, but also that environmental disasters in nuclearized regions can arise from serious climate events as well as natural disasters.

It is sometimes suggested by grim environmental pundits that if climate change doesn't get us then nuclear destruction will. Concerned pessimists about the effect of nuclear power on humanity have been vocal from the beginning, since the dropping of atom bombs on Japan in 1945. But it remains an interesting question what the effect of climate change on the nuclear industry will be. When the Fukushima disaster occurred, fear about its environmental effects was immediate. A release of radioactive materials in the atmosphere and in the ocean followed the 2011 Japanese tsunami, which damaged the nuclear plant, resulting in serious hydrogen gas explosions and partial meltdowns. The large-scale release of radioactivity resulted in the evacuation of about 100,000 people from a twenty kilometre exclusion zone set up around the power plant, similar to the thirty kilometre radius Chernobyl Exclusion Zone still in effect. Today, radioactivity levels have lowered enough to have a limited impact on wildlife. Radionuclide concentrations are stable in the marine environment near the nuclear plant; 
traces are visible in the air. Since the accident, radionuclide measurement results of foodstuffs produced in Japan have lowered. In Japan, in July 2016, Fukushima Prefecture announced that the number of evacuees had fallen below 90,000, partly as some municipalities lifted evacuation orders, but interestingly about 33,000 people have chosen not to return to their homes out of fear and distrust. Even these data were very difficult to obtain, as Claude-Yves Charron shows in Chapter 8.

Politicians are not dealing adequately with climate change today. The Paris Agreement was an achievement, but even in the US President Trump was an effective climate change denier until he was replaced. In Canada we clearly are not going to meet our targets for carbon reduction which we committed to. Climate change is more evident already to everyone, with daily environmental disasters occurring - including floods, droughts, fires, wind storms, etc.

What precautions are being taken to ensure that nuclear plants remain safe and do not explode in this disruptive era? How do the facts of climate change affect the nuclear industry in nuclear nations? Are nuclear scholars sensitive to this environment as they research and write? Are archivists reflecting on how this new environment may result in new issues that scholars will want to study with their assistance?

Both nuclear issues and climate change are serious challenges that we cannot neglect. In this era of climate change, it is important for politicians and the public to keep informed about nuclear energy as they explore alternative energy sources. What role nuclear energy will play in that scenario is an interesting and controversial question. But more needs to be done now in the academic field, and hopefully research will expand on nuclear subjects, and on the 
relationship between climate change and nuclear issues. NIRG remains a useful tool to encourage the expansion of such critical research, but what new directions it takes in the future will probably depend on the relationship between nuclear energy and climate change.

Which climate and political forces are influencing the nuclear nations? How will climate change stimulate future scholarship? Are nuclear scholars examining this new situation? Scholarly work and archives on all aspects of nuclearism hopefully will expand, be well publicized and grow the field and public awareness of it.

NIRG began with thoughts about the relationship between nuclear energy and climate change. What it has become today and what new directions it takes in the future probably will depend on that same relationship. 


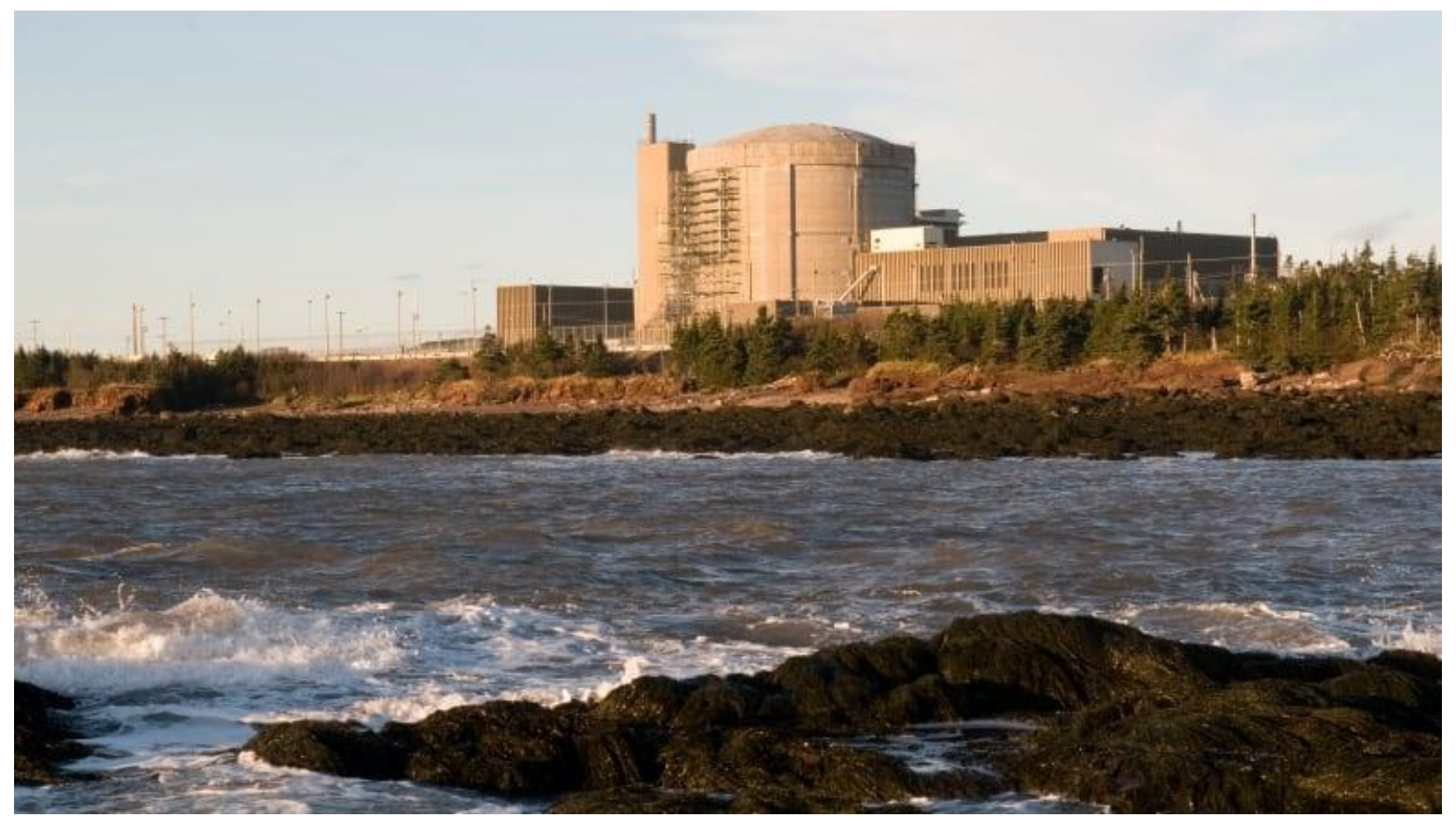

Figure 1. Point Lepreau CANDU Six 705 megawatt reactor in New Brunswick Canada in 2020, then running above 90\% capacity. It was commissioned in 1983 and refurbished in 2012. Although renovation was supposed to begin in 2008 the whole process was itself delayed by operating problems so that renovation actually began in 2011 and took a year. Cost over-runs and insurance problems delayed its re-start. Apart from well-known environmental sustainability questions, Point Lepreau is a text book-case on the difficulty of successfully operating a reactor of this size, triggering both planning and financial issues. The high cost of insurance for the renovated reactor was confidential, adding to the cost of a unit of electricity from Point Lepreau. As the cost was difficult to measure, it is thus difficult to compare it with other reactors, particularly with respect to its contribution to climate change. The original Point Lepreau reactor was built long after the early CANDU reactors were installed in Ontario, India, Pakistan, Korea and Argentina. (NB Power, Point Lepreau nuclear generating station, photograph published Jan 28, 2021 by CBC news, https://www.cbc.ca/news/canada/newbrunswick/lepreau-nbpower-nuclear-plant-1.5890989. Image used with permission. Rights belong with NB Power.) 
${ }^{1}$ Professor Allison Macfarlane is now [2022] Director of the School of Public Policy and Global Affairs at the University of British Columbia, Vancouver. 